\title{
Cordonnier Grade 3 Parasitic Complication, Pneumocystis jiroveci Pneumonia
}

National Cancer Institute

\section{Source}

National Cancer Institute. Cordonnier Grade 3 Parasitic Complication, Pneumocystis

jiroveci Pneumonia. NCI Thesaurus. Code C138312.

Any Pneumocystis jiroveci pneumonia. 